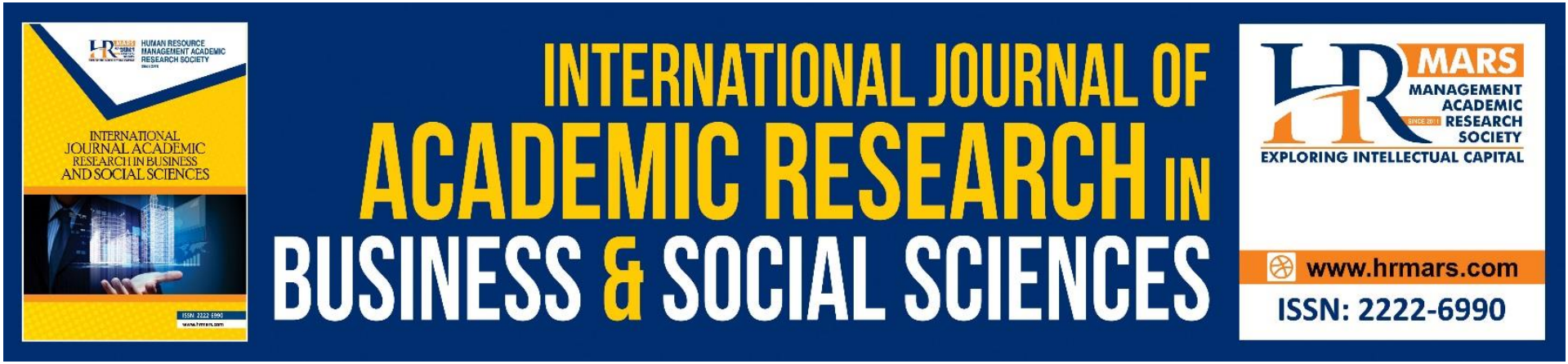

\title{
A Study on How Media Impacts Society and Whether Upcoming Media Professionals Should Use Media to Influence Others
}

Mercy Munene

To Link this Article: http://dx.doi.org/10.6007/IJARBSS/v11-i3/8495

DOI:10.6007/IJARBSS/v11-i3/8495

Received: 30 January 2021, Revised: 27 February 2021, Accepted: 10 March 2021

Published Online: 20 March 2021

In-Text Citation: (Munene, 2021)

To Cite this Article: Munene, M. (2021). A Study on How Media Impacts Society and Whether Upcoming Media Professionals Should Use Media to Influence Others. International Journal of Academic Research in Business and Social Sciences, 11(3), 923-931.

\section{Copyright: @ 2021 The Author(s)}

Published by Human Resource Management Academic Research Society (www.hrmars.com)

This article is published under the Creative Commons Attribution (CC BY 4.0) license. Anyone may reproduce, distribute, translate and create derivative works of this article (for both commercial and non-commercial purposes), subject to full attribution to the original publication and authors. The full terms of this license may be seen at: http://creativecommons.org/licences/by/4.0/legalcode

Vol. 11, No. 3, 2021, Pg. 923 - 931

Full Terms \& Conditions of access and use can be found at http://hrmars.com/index.php/pages/detail/publication-ethics 


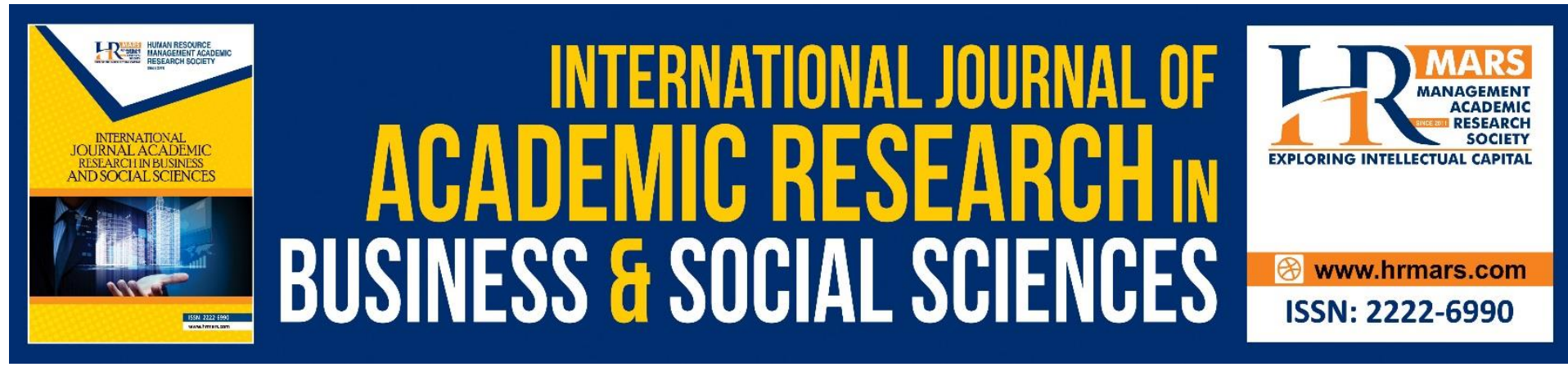

\title{
A Study on How Media Impacts Society and Whether Upcoming Media Professionals Should Use Media to Influence Others
}

\author{
Mercy Munene \\ PhD student at Jomo Kenyatta University of Agriculture and Technology
}

\begin{abstract}
Every Kenyan listens to or watches different forms of media every day. Evidence indicates that an ordinary Kenyan citizen is accessible to media that may come in the form of print, radio or television. Besides, not only is every Kenyan accessible to media, but also a typical Kenyan spends several hours in a day to media. The increasing number of hours Kenyans spend exposed to some kind of media raises the question 'What is the impact of Media in the society and how media use influences others.? The study aimed to identify university students' attitude towards effects of media to societies and use of media to influence others. Thus, the paper begins with a literature review supporting the impacts of media in the society and how media use by professionals influences others. The sample size includes 150 students from University of Nairobi. The time frame for this survey was between September to November 2020 and a questionnaire was used to collect adequate data from the targeted participants. From the analysis, the results shows that media impacts society in both positive and negative ways, and many students are willing to use positive messages in media to influence others positively. The discussion and conclusion summarize that media professionals should appreciate media as a tool for transforming societies.
\end{abstract}

Keywords: Media Professionals, Society, Media, Impacts of Media etc.

\section{Introduction}

The television, radio and print media have great influence in the society today. Various studies have been conducted on the impact of the media on the society and scholars and academicians have had different contrasting views on the role of media in the society. Among the studies conducted include those on the influence of violence on attitude and behavior, impact of sexual content and nudity as well as the impact of unregulated alcohol commercials among others. While the media has some potentially negative effects, it also has positive implications in regard to behavior development and growth among children and teenagers (Anderson \& Subrahmanyam, 2017). Also, as a result of rampant globalization and emergency of new technologies, the impact of the media and its influence on others is more than ever before in Kenya. In this connection, this research study examines the impact media influence in regard to its effect in sexual content and nudity, alcohol as well as violence. Apart from this, the study also establishes what the influence of media has to others. 


\section{Statement of the Problem}

Societies are defined by their cultures, morals and values. However, as a result of the increasing exposure to media among Kenyans, scholars believe that the media has influence on the society and perhaps a reflection of our society. Evidence indicates that media has positively and negatively influenced the society we live in. Appropriate structures and initiatives to control what is aired on media lack in Kenya. As a result, violence, alcohol and sexual content are common in the Kenyan media. A media filled with violence, alcohol and sexual content negatively corrupts our culture, morals and values as a community and a country. In this connection, this study seeks to determine the impact of media in the society and discussion on whether upcoming experts in field of mass communication can use media to influence others.

\section{Research Question}

What is the impact of Media in the society and how does media influence others?

\section{Research Objectives}

1. To identify impact of media on the society.

2. To identify how media professionals use media to influence others.

\section{Literature Review}

The media has significantly impacted on the society as in various ways due the increase in uncontrolled alcohol advertisements, sexual content and nudity in television programs and music, and violence just to mention a few.

Thoughts and ideas aired or communicated visually via television tend to be very powerful in regard to influencing an individual's behavior or actions. The recent census report by the Kenyan National Bureau of Statistics (KNBS) indicated that radio and television are found in a majority of Kenyan households. Also, statistics indicate that television viewing among Kenyans has increased in the last two decades. This is especially high among the young generation comprising teenagers and the youth. Averagely, it was established that an ordinary Kenyan family watches three to four hours of television every day (Mehraj, Bhat, \& Mehraj, 2014). Radio and television are regular sources of information and entertainment among Kenyans. However, a recent study established that unlike radio and the print media, television has the greatest impact in regard to influencing people's views and their understanding of the world.

Various studies have been conducted to determine the influence of media on the society with the effect of media on violence among children and youths being among the most studied aspect. All studies conducted on this particular topic established that violence on television has a negative influence, especially among the children and youth. The increasing violence in the media has proven to be detrimental. For instance, most recently, a 21-year-old university student murdered some of his family members in cold blood citing inspiration from a TV show and two homicide novels he read. This clearly indicates that violence in media has an ability of negatively influencing others and promoting violence behaviors among Kenyan teenagers and youths. Additionally, a recent report from the Kenyatta National Hospital indicated that the mass media is among the many potential causes of aggression and bitterness. The report indicated that teenagers and youth who portray aggressive tendencies often have a history of watching violent content in the media. Moreover, unlike other forms of media, television violence is considered to be more 
influential. This is so because an average of five to six acts of violence appears on prime-time television every hour. In this particular context, violence refers to acts of violence such as shooting, fighting, murder, rape and car wrecks among others. Studies indicate that violence is associated with fear of victimization and desensitization of aggressive behavior. A recent study by Hepp, Hjarvard and Lundby (2015), denotes that Kenyan youths and teenagers in the contemporary world tend to be more desensitized to acts of violence as compared to those from previous generations. As a result, being desensitized to violence indicates that teenagers and youths are more accepting and used to acts violence and for that reason are more willing to watch media containing violent content. Desensitization towards aggression is also associated with a decreased willingness to help victims of violent and aggression. Fear of becoming a victim on the other hand results to mistrust thus causing self-protective behaviors which also entails violence. Another study by Ngula, Mberia, and Miller (2016), established that at least $10 \%$ of all violent cases among teenagers and youths is positively correlated to watching television. Moreover, it was established that majority of heavy television views barely realize that the changes in behavior and its overall impact in their dayto-day activities. Furthermore, video games that entail role playing where players' fight, shoot and kill each other have also been identified as potential causes of violence among individuals in the society. Various studies on violent video games indicate that they tend to trigger aggressive thoughts, increase anxiety levels and hostility among other violent behaviors.

Music is powerful tool with an ability to influence thoughts and actions of individuals. For that reason, music another potentially influential aspect of the media. This is so because of the unique ability that music has in shaping ideas and popularizing certain behavior. Several studies indicate that music has potentially negative effects. For instance, heavy rock and rap is related to aspects of vandalism, drug use and aggression among others. However, it is essential to note that even though rap and heavy rock are associated with vandalism and drug abuse, certain types of music such as jazz, and soft music is instrumental in relaxation and setting the mood for romantic and sexual arousal. Besides, Bidabadi and Mehryar (2015), denotes that music is plays a vital role in easing anxiety and depression. In other words, music improves cheers and improves the mood of sad and depressed individuals. Also, it was established that individuals listening to uplifting and prosaically positive songs registered a greater willingness to help as well as increased empathy.

Increased sexual content in television has also risen concerns about its potential effects in the society. A research done on sexual content and nudity established that a majority of sex scenes in television do not conclude that sex before marriage is wrong this encouraging the desirability of sex before marriage (Booker, Miller \& Ngure, 2016). Likewise, a study on the relationship between exposure to sexual content and nudity established that teenagers and with watching sexual content are more likely to be having sex as compared to those that watch less or no sexual content. Also, a majority of sexual content and nudity in the media tend to make sex appear desirable without necessarily highlighting some of its negative effects such as unwanted pregnancies and the risk of sexually transmitted infections just to mention a few.

Apart from sexual content and nudity, alcohol, especially alcohol advertisement is increasing in the Kenyan media. Commentators believe that advertisements of alcohol greatly influence how people choose to drink. Also, many studies support the claim that the media has a great influence on thoughts and behavior of the youth in Kenya. This is in line with the 
'effects' model which suggests that when alcohol is seen as normal and a 'cool' thing to do, people are more likely to consume it.

While a majority of studies on the impact of media are on the negative influences such as sexual content and violence, various studies have also been conducted on the positive impact of the media in the society. For instance, a recent study on high school students established that students watching pro-social content in television tended to behave better in social situations around their peers. In summary, the study concluded that television has an impact of encouraging and fostering positive attitudes and social interactions.

\section{Method}

To come up with adequate data on the effect of media and whether professionals can use media to influence others, a quantitative research design was used. The participants for this study were students from the University of Nairobi in the department of Mass Communication. More than 150 students from different levels of study were asked to participate in the study. There were 50 fourth-year students, 60 third-year students, 25 second-year students, and 15 first-year students. Also, the respondents were equal that is $48 \%$ male and $52 \%$ females.

During the study, it was observed that most of the sources used in the literature review investigated television, but in this study, it was found that most of the students at the University of Nairobi could access computers, televisions, and radios. Therefore, to be within the research topic, the respondents were asked to provide their views on movie viewing traits as it was noted that movies were commonly watched media contents in the campus. Besides, it was observed that movies were readily available for the students on their laptops, mobile phones, in their residential areas, and also in school theater. Television and movies air the same content such as alcohol abuse, sexual innuendo, reality, sex scenes, violence, and language.

Therefore, research questionnaires were designed and this included both soft copies and hard copies. Those participants who were unable to access hard copies were asked to use soft copies and vice vasa. In the questionnaire, there were four questions whose main theme was to investigate the type of content watched by students in the movies and how they have used ideas borrowed from the media to influence others. Thus, the entire questionnaire wanted to know viewing habits portrayed by the respondents, by asking them how often they have been watching movies, the number of movies they have been watching have violence, the number of movies they have been watching containing profanity, and the number of movies they have watched that contain obscenity. The aim of asking all these types of questions was to determine the ethics and mindset these students have when it comes to various content in media. The content aired by these media contents determined the moral values exhibited by the students as media professionals in the future.

Additionally, the second question focused on how students were influenced by the media. The question was Do you think media content interferes with your morals.? At this level, the study wanted to know whether media content watched impacted aspects such as student's moral values, self-esteem, and social norms. The question appreciated Yes or No answers. The third question was; If you were creating a production, what type of content will you include or exclude in your production.? This question aimed to identify material that could be included or tolerated by the students as media professionals. The University of Nairobi is a recognized institution with dignity and one anticipates learners from this institution to uphold moral integrity. Lastly, the questionnaire targeted to know if students 
have intentions to influence others through the use of media what type of influence, they deem to be appropriate. At this level, this study used open-ended questions thus helping in the exclusion of relevant responses. All these questions used in the questionnaire helped in coming up with robust results as outlined below.

\section{Results}

The results obtained were based on the main topic of each question used in the questionnaire. First and foremost, when it came to how the students will influence their colleagues and the society at large through media, different results were obtained. In the findings, it was observed that $76 \%$ of the participants would influence their classmates with positive information. This indicated that participants will reflect positive morals to the society after watching different materials from their computers, televisions, and in the school's theater. According to the participants, they will use different media such as televisions, radios, and music to spread positive information that will aid in refraining from watching those materials that interfere with moral values. Also, it was indicated that $21 \%$ of the students in the university were oblivious to how to influence their classmates with messages obtained from the media. However, nine participants argued that they will be broadcasting Tv shows and radio programs to communicate how aspects such as drug abuse are dangerous to society.

Besides, when it came to content that can be allowed in the media, the study obtained the following results. First of all, $80 \%$ of the participants argued that if they were to be involved in the production of media content in studios, they would not allow the audience to watch iniquitous aspects such as sex-related materials in their production. Furthermore, it was observed that many of the students $(90 \%)$ supported media content with war violence in the media but only $10 \%$ were watching general violence on their computers and televisions. Also, this survey found that a large number of students at the University of Nairobi believed that materials with war violence content should be allowed in media. These results summarized that war violence was of more interest as compared to general violence. Moreover, in the first question, the study emphasized how often and type of content is watched by students on their media platforms. The investigation found that $39 \%$ of the total participants fairly often watch movies and also found that no one was not using media. Besides, $58 \%$ of the participants' respondent that they have been watching movies with sex on their laptops and televisions. When students were asked whether they have been watching movies with war violence, $69 \%$ responded yes. Likewise, when students were asked whether they have been watching materials with obscenity, $40 \%$ revealed that they occasionally do so, and $21 \%$ indicated they rarely watch media content with obscenity. Based on these results, the survey realized that materials with sex and obscenity were highly watched by the students from the University of Nairobi.

\section{Discussion of the Results}

The results obtained in this study concluded that the values and morals of the students were not impacted by the different materials watched in media. The results articulated that the influence of media content on human attitudes and behavior is a topic that societies have to pay much attention to. Concerning this study, it was discovered that a large number of students had self-immunity when it comes to content and materials watched in media. According to Gripsrud (2015) media has been identified as one of the aspects that are changing human behavior and attitudes. However, this study noted that $80 \%$ of the 
respondents believed that content watched in media does not interfere with their moral values in society. Similarly, the results indicate that at some points media includes morally upright content that can be used to spread good values and morals in societies. For example, DellaVigna and La Ferrara (2015) cites that media platforms such as TV's and radio airing Christian related information have been on the frontline changing societies on those values that promote social cohesion.

Consequently, the participants believe that materials and content broadcasted by media can influence and reinforce a change. According to the students, it is clear that media experts believe that media can be used as a tool to make a change in societies. Most of the professionals in this field as it is illustrated by Waldfogel (2017) are willing to use media to transform societies positively. It has been outlined that media forms the significant part people time whereby people averagely spend more than $30 \mathrm{hrs}$ watching television and their computers (Oviedo et al 2015). This shows that people have to select those contents and materials that in one way or another they do not impede with upstanding virtues (Anderson \& Subrahmanyam, 2017). The students in the study supported that media is a tool to influence others and that is why most of them revealed that they will use media to spread positive information only.

Additionally, the results revealed that most of media professionals want to influence societies positively. The survey shows that $76 \%$ of the students want to use media as a tool for broadcasting aspects such as violence and drug abuse. Ten participants in this study argued that they will use radios and televisions to broadcast programmes supporting violence and drug abuse. According to Bursztyn and Cantoni (2016), these programmes will help in reflecting positive behaviors that will help as much as possible to instill morals and values. McLeod et al (2017) illustrated that most of the TV programmes supporting war violence and other unethical practices serves as sign of teaching the negative effects of these contents to the audience. This outlines that some media platforms despite choosing negative content, tend to communicate to the viewers that this is not good at all. Raney et al (2019) concludes by supporting that we have reinforcement theory that dictates that media violence reduces the probability of violence by the audience. The fact is that negative aspects such as drug abuse, sex, and violence are everywhere and therefore media should broadcast everything the way it is but viewers should make their decisions on the right direction to follow (Caprì et al 2019).

\section{Conclusions and Recommendations}

Although most of the arguments raised in this study primarily focused on the unhealthy impact of media on societies, some media programmes have been on the frontline promoting viable attitudes and behaviors in societies. The survey outlines that half of the participants are willing to use media content to influence their classmates with positive information. Consequently, it was observed that some students are unaware on how to use messages and other ideas borrowed from media to change others in societies. On the other hand, when it came to content that should be allowed in media, participants argued that if they were to be involved in production of media content in studios, they would not allow audience to watch programmes that airs sex related themes. In contrast, some participants argued that if allowed to work in production studios they will air media content with war violence and obscenity. This groups argues that by allowing audience to watch aspects such as drug abuse, media with obscenity and war violence, it becomes easy for viewers to reflect negative impacts and then decide on best directions. The theoretical framework of this study 
illustrates that media is a tool that should be used to bring positive change to audience. As it is supported by La Ferrara (2016), the content and materials coming from media has to focus on morals and reality. Similarly, media users have to spread positive ideologies that supports upright behaviors.

Therefore, it can be recommended that media platforms such as television, radios, and computers can be used to broadcast apt contents and materials that transforms societies appropriately. The fact is that media is the best platform that can reflect on what is morally upright to people. In addition, we suggest that future investigation should be carried out to determine the causation of these human-related attitudes and behaviors induced by media. Ideally, all ideas borrowed from media dictates various aspects in humans and therefore, a future study should be carried out to determine to what extent these contents impact personal attitudes and behaviors. Lastly, media with contents supporting aspects such as drug abuse, sex and other aspects contrary to societal norms and values should be monitored. Rules and policies should be enforced to control broadcasting of those media contents that interferes with societal norms and values. By doing all these it becomes easy to appreciate the importance of using media as a tool for inducing positive values to audience.

\section{References}

Anderson, D. R., \& Subrahmanyam, K. (2017). Digital screen media and cognitive development. Pediatrics, 140(Supplement 2), S57-S61.

Bidabadi, S. S., \& Mehryar, A. (2015). Music therapy as an adjunct to standard treatment for obsessive compulsive disorder and co-morbid anxiety and depression: A randomized clinical trial. Journal of affective disorders, 184, 13-17.

Booker, N. A., Miller, A. N., \& Ngure, P. (2016). Heavy sexual content versus safer sex content: a content analysis of the entertainment education drama Shuga. Health communication, 31(12), 1437-1446.

Bursztyn, L., \& Cantoni, D. (2016). A tear in the iron curtain: The impact of western television on consumption behavior. Review of Economics and Statistics, 98(1), 25-41.

Caprì, T., Gugliandolo, M. C., lannizzotto, G., Nucita, A., \& Fabio, R. A. (2019). The influence of media usage on family functioning. Current Psychology, 1-10.

DellaVigna, S., \& La Ferrara, E. (2015). Economic and social impacts of the media. In Handbook of media economics (Vol. 1, pp. 723-768). North-Holland.

Gripsrud, J. (2015). Television. The international encyclopedia of political communication, 110.

Hepp, A., Hjarvard, S., \& Lundby, K. (2015). Mediatization: theorizing the interplay between media, culture and society. Media, culture \& society, 37(2), 314-324.

La Ferrara, E. (2016). Mass media and social change: Can we use television to fight poverty? Journal of the European Economic Association, 14(4), 791-827.

McLeod, D. M., Wise, D., \& Perryman, M. (2017). Thinking about the media: a review of theory and research on media perceptions, media effects perceptions, and their consequences. Review of Communication Research, 5, 35-83.

Mehraj, H. K., Bhat, A. N., \& Mehraj, H. R. (2014). Impacts of media on society: A sociological perspective. International Journal of Humanities and Social Science Invention, 3(6), 5664.

Ngula, K. W., Mberia, H. K., \& Miller, A. N. (2016). Parental mediation of adolescent media use and demographic factors as predictors of Kenyan high school students' exposure to sexual content in television. African Journal of AIDS Research, 15(1), 1-8. 
Oviedo, V., Tornquist, M., Cameron, T., \& Chiappe, D. (2015). Effects of media multi-tasking with Facebook on the enjoyment and encoding of TV episodes. Computers in Human Behavior, 51, 407-417.

Raney, A. A., Janicke, S. H., Oliver, M. B., Dale, K. R., Jones, R. P., \& Cox, D. (2018). Profiling the audience for self-transcendent media: A national survey. Mass Communication and Society, 21(3), 296-319.

Waldfogel, J. (2017). How digitization has created a golden age of music, movies, books, and television. Journal of economic perspectives, 31(3), 195-214. 